\title{
Diagnostics of Educational Activity Quality on the Basis of Qualitative Methods
}

\author{
Elena Yuryevna Levina ${ }^{1}$, Linar Gimazetdinovich Akhmetov $^{2}$, Liliya Nikolaevna Latipova ${ }^{2}$, Alsu Linarovna \\ Mirzagitova $^{2}$, Fairuza Ismagilovna Mirzanagimova ${ }^{2}$, Zagir Azgarovich Latipov $^{2} \&$ Alfiya Rafisovna \\ Masalimova $^{2}$ \\ ${ }^{1}$ The Institute of Pedagogic and Psychology of Professional Education of Russian Academy of Education, Kazan, \\ Russian Federation \\ ${ }^{2}$ Kazan Federal University, Kazan, Russian Federation \\ Correspondence: Elena Yuryevna Levina, The Institute of Pedagogic and Psychology of Professional Education \\ of Russian Academy of Education, Isaeva Street, 12, Kazan, 420039, Russian Federation. E-mail: \\ frau.levina2010@yandex.ru
}

Received: September 30, 2014 Accepted: December 27, 2014 Online Published: January 14, 2015

doi:10.5539/ass.v11n4p246

URL: http://dx.doi.org/10.5539/ass.v11n4p246

\begin{abstract}
The purpose of this article is to research a problem of diagnostics of educational activity efficiency quality increase in professional educational institutions. Presented article shows a technique of diagnostics of educational processes quality on the basis of educational activity results. The concept of general quality management (TQM) acts as the basis of the presented work. It provides the development and continuous improvement of educational activity quality. Quality indicators of educational process and methods of their estimation allow carrying out diagnostics of educational activity and they are given in the article. This article is intended for teachers, researchers, heads of the educational institutions dealing with issues of assessment and improvement of education quality.
\end{abstract}

Keywords: professional education, quality management, diagnostics, qualitative, indicators

\section{Introduction}

Quality of training as the scientific and theoretical problem includes economic, social, informative, cultural aspects of education and it is the integrated characteristic of educational activity of any educational institution. One of the key directions of change and improvement of system of professional education is improvement of quality of management by education, rapid response to changes of requirement for experts and implantation of new forms of education (Muhametzyanova, 2005; Ibragimov, 2002; Novikov, 2009, et al.).

Management of education development causes creation of diagnostics quality system with coverage of all its objects and various measuring means, tracing set of characteristics of used pedagogical technologies.

Modern practice of automated management introduction systems and the account in higher education provide information support of adoption of administrative and financial decisions, educational activity, implementation of innovative projects in education and the scientific activity in a whole. It promotes the increase of effective management of educational institution (university) at all levels (Matros, 2008; Potashnik, 2002; Yakovlev, 2002, et al.).

The main concepts of the organization of such system are the following: introducing integrated electronic document flow; creation of the information systems exercising control of the students' contingent. That means accounting of progress and attendance, grant calculation, lesson schedule formation, etc.; development of the system of a portal of the university that includes systems of the main professional tasks, the description of technologies and ways of their solving by students, systems of testing of students, providing distant users with the knowledge and syllabus content; introduction of system of information and analytical support of quality management of specialists training, organization of continuous monitoring of the quality of education coordinated with curricula and schedules, preparation of information and analytical materials about quality of education of students and graduates. Such system has to provide not only efficiency, accuracy and reliability in 
information transfer, but also to supply university management by means of planning, control and the analysis of results of all kinds of activity.

However in our opinion, existing concepts of information high school systems and their practical realization don't provide an objective and timely assessment of educational activity of teachers and students. It should be noted that at the level of quality standards generalized description of the pedagogical phenomena and regularities is obviously not enough for estimation of these processes and establishment of its properties. All this and also a great deal of arriving documentary data demand application of the mathematical methods. The complexity of using these methods is that any object in pedagogic is extremely changeable and the subject is influenced by many random factors. Therefore development of necessary and sufficient objective checking technologies and also standard of estimation of studied processes and mathematical support seems to be actual one (Subetto, 2000; Rudinskiy, 2004; Avanesov, 2005; Ingekamp, 1999, et al.). It allows analyzing a course of occurring changes, establishing of necessary for management training quantitative dependences between the studied phenomena, to predict tendencies of development and activity prospect. Also it is necessary to develop and propose administrative solutions. The structure of basic approach to quality management of educational process has to provide the only treatment of its components, properties, parameters, technology. Thus the approach has to possess properties of universality, to be aimed at effect of introduction, to provide the set roles of all participants of educational process, and also technological effectiveness and measuring ability of educational process at all its stages.

\section{Methodological Framework}

The purpose of experimental research was to determine such parameters of educational activity (indicators) which could reflect fully a course, features and deviations of educational activity from planned results.

The analysis of a condition of quality training problem is carried out taking into account a world tendency to extend methods and means of international ISO 9000 standard and the concept of general quality management (TQM), applied earlier in a services sector and in the industry, in a control system of quality of education (Bermus, 2002; Nuzhdin, 2003; Kaynova, 2005; Gorbashko \& Bonyushko, 2011; Selezneva, 2002, et al.). The tendency is market-oriented and is focused on searches and expeditious elimination of weak points in educational process, initiates intuition power base, wide-ranging studies and the analysis of qualitatively new ideas to provide the maximum compliance of reached levels of training (FGOS).

Initial idea was that a key factor of modern pedagogical technologies as a combination and sequence of methods and transformation processes with the parameters and properties is the fact of achievement of the end result and control of accuracy of its achievement. Really, the results of higher education students knowledge control comprise not only personal achievements of students (their ability, motivation, readiness for training, educational level), but also internal indicators of process: quality of educational activity (quality of the teacher, educational technology, methodical and control means) within educational institution, the direction of specialty, definite subject, a module or a theme.

The gain score of students is chosen as display of achievement result of an ultimate goal and indicators of training quality. So the main trait of control of knowledge is reflection of all regularities in it and characteristics of educational activity of a teacher and a student as the parameters of system of diagnostics is chosen in this research. On the one hand it is the only feedback indicator with students; on the other hand it is the certain numerical indicator that has one of four marks ("excellent", "good", "satisfactory", "poor"). Estimation of each student separately can give the characteristic only personally, but estimation of group of students as some system where the same procedures of training and control were provided to each element promotes an assessment of the process of training, classification of the teacher, maturity of technology of training and control of knowledge in a whole. Thus the complex of descriptive statistical parameters as indicators of quality is offered. The parameters are: a GPA for group, dispersion, a mean square deviation, asymmetry and excess coefficients which reflect a tendency of statistical distribution in results of educational activity.

The qualitative approach includes: measurements in a numerical form or in conditional indicators; the combination of methods of the research aimed at obtaining versatile object data, tracking dynamics of indicators change and the analysis of possible deviations. They will provide transition from the qualitative, unilateral description of the phenomena to objective, exact methods of checking and generalization of results of pedagogical activity at a higher educational institution for adoption of the adequate administrative decisions, capable to increase quality of educational process in higher education. 


\section{Results}

Collecting of experimental data (degree of students' education, based on statistics of the estimates received by them at the current or total control was made for the research of process of educational activity at a higher institution, findings of indicative quantitative indices of training quality which it is possible to apply qualitative approaches to. Statistical data, about 3000 sets of total knowledge control papers at the universities of Kazan (federal, technical, technological, power) on subjects of engineering, humanitarian and economic direction were used as experimental data.

In the course of monitoring the data coming to computer base, were processed, systematized, statistical parameters for each studied educational group of students were calculated: GPA, dispersion, mean square deviation, asymmetry and excess coefficients.

Calculation of the corresponding characteristics was accompanied by creation of distributions of points in the form of the histograms displaying percentage ratios of points (estimates of various denominations) in group (the example is given in Figure 1).

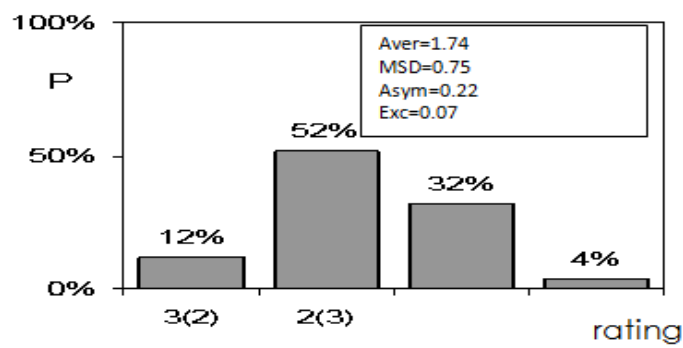

Figure 1. Distribution of points in a student's group on a subject "Engineering graphics" (here "Aver"-an average value, "MSD"-a mean square deviation, "Asym"-asymmetry coefficient, "Exc"-excess coefficient)

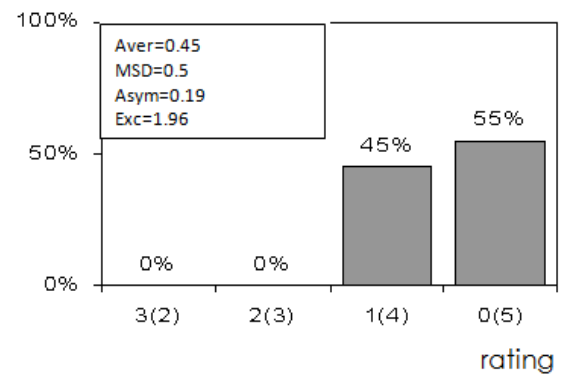

Figure 2. Distribution of points (marks) in a student's group on a subject "Philosophy"

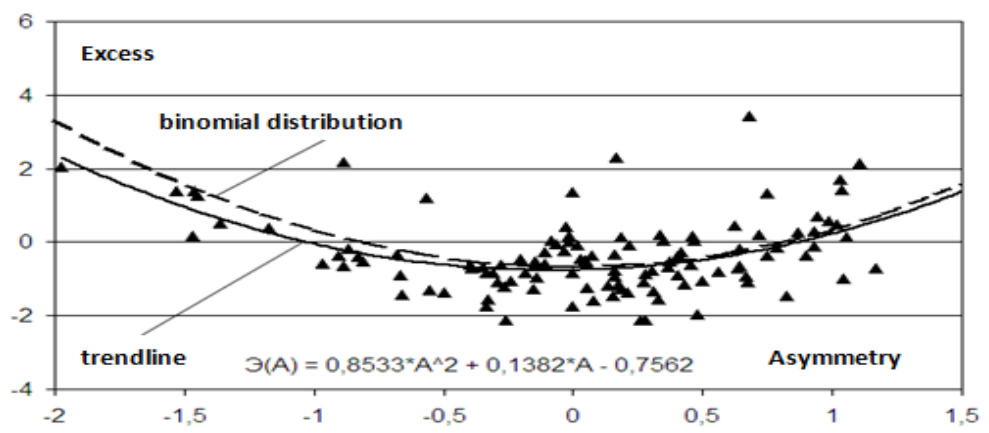

Figure 3. Results of diagnostics of training quality according to a method of the moments

As a result the analysis of 3000 knowledge control papers the intervals of meanings (in which the main shares of data recording are concentrated) are defined; rare combinations of statistical parameters (Figure 2 (obviously overestimated indicators)) are investigated; the pedagogical reasons of these deviations are found and analyzed. 
The method of the moments was used in the analysis of descriptive statistics. It provides the search of deviations in result data of students' groups control adapted for pedagogical measurements. The diagram of coefficient dependence of an excess from coefficient of asymmetry (Figure 3) was made.

Having investigated a great amount of knowledge control results, it is possible to notice a tendency of group of points in the field of parabolas, characteristic for binomial distribution. Thus it is revealed that if the point, that is a result of control in one students' group, considerably breaks the schedule, it testifies to the anomalies arising in educational process.

Consideration of conditions under which the corresponding extreme rejections of data took place, showed that combinations of circumstances, atypical enough for educational process and demanding the detailed analysis of a pedagogical situation for correction of process of training or control (for example, unreliable control tests, violation of a course of the educational process, insufficient qualification of teachers, not adjusted pedagogical technology of training and so forth) are the reasons of deviations.

It is shown that a complex of statistical parameters can be used as quality indicators, characterizing maturity of educational process, and statistical methods of their assessment can be decisive rules in the diagnostic automated system, in the process of accumulation of data meanings are specified, there is a differentiation on subjects, the directions of training and educational institutions.

As a task of applied qualimetry is development of concrete techniques and mathematical models for an assessment of objects quality of a different look and appointment, on the basis of the obtained data the algorithm of estimation of quality of educational activity in professional education is developed:

Stage 1. Assessment of the nomenclature of single quality indicators of estimated process. Indicator of quality is the quantitative characteristic of property of the object which is a part of its quality and considered in certain conditions of life cycle of the object. For educational activity, as a process, quantitative assessment is an indicator of progress of students' groups, its nomenclature is conditions of preparation and carrying out educational activity.

Stage2. Choice and determination of basic indicators meanings of training quality, on the basis of a choice of a sample (models) of process. As basic indicators on the basis of the law of "large numbers" in this research values of meeting descriptive indicators are chosen most often.

Stage 3. Determination of values of single quality indicators on the basis of these tests of measurements and if necessary, calculations. Data of control are entered and are estimated, calculation of indicative indicators (on the basis of formulas of mathematical statistics) is made at this stage again.

Stage 4 . The analysis of the firstly entered data on the basis of methods of mathematical statistics (a method of the moments and a method of three sigma), allowing to trace possible rejections of entered data from lines of normal meanings. The methods of the progress indicators analysis of adapted for pedagogical measurements allow making the analysis of highly reliable data.

Stage 5. Assessment of quality of process and adoption of the administrative decision. The presented qualitative system of diagnostics allows defining of the result of educational activity course on a certain subject that allows making the administrative decision in need of educational process correction, or pedagogical technology.

Thus, the complex of quality indicators (descriptive statistics is developed and almost realized: average value, mean square deviation, excess and asymmetry coefficients) for the registered intermediate and total gain scores in students' groups and methods of their assessment (a method of "three sigma" and a method of the moments), allowing to estimate results of control on each subject from the point of view of diagnostics of training quality.

\section{Discussions}

The subject of the present research is based on achievements of pedagogical science in standardization, technology and quality management. G. V. Mukhametzyanova (2005), G. I. Ibragimov (2002), D. A. Novikov's (2009) works, etc. are devoted to research of pedagogical processes and the phenomena. Development of standards of professional education, introduction of system of ISO in educational activity is shown in D. Sh. Matros (2008), A. G. Bermus (2002), V. N. Nuzhdin (2003), E. B. Kaynova (2005), E. A. Gorbashko, N. A. Bonyushko (2011) works, etc. Questions of technologization of educational process and development of pedagogical aspects of the theory of management are considered by N. A. Selezneva (2002), M. M. Potashnik (2002), E. V. Yakovlev (2002), etc. Features of application of methods of mathematical statistics in pedagogical researches and ways of pedagogical measurements and diagnostics are considered in V. S. Avanesov (2005), K. Ingenkamp (1999), A. I. Subetto (2000), I. D. Rudinsky's (2004) works, etc. 
However, despite existence of scientific works on problems of quality training diagnostics the productive and standardized mechanism of measurement and an assessment of quality of training, including, educational programs, methods and results of training is insufficiently developed in Russian education system. Absence of objective standards of educational activity level leads to the existing assessment of quality of objects of educational system represents the insufficient indicator for adoption of the relevant administrative decisions. Besides, possibilities of use of mathematical methods are insufficiently reflected in work of control systems as quality of educational activity. Due to the mentioned above, as the problem demanding the paramount decision, it is necessary to specify development of mathematical, methodical and information support of monitoring and diagnostics, that is, a tool, allowing to observe and to analyze statistical data in a course of process of training quickly; to predict tendencies, to estimate prospects of educational activity and a consequence of correcting influences without additional measurements.

\section{Conclusions}

Thus, we proved qualitative assessment of pedagogical processes promoting obtaining new diagnostic information, increase of reliability of conclusions, allocation of the main tendencies and creation of generalizations in the course of research of this problem.

Offered qualitative methods of estimation are applicable at all levels of management of educational activity in professional education:

- For a teacher: control of his or her activity and result of adaptation of a course, especially for those subjects which scheme of teaching undergoes frequent changes, possibility of fast debugging of pedagogical tests.

- For heads of the department: an assessment of activity of each teacher, detection of efficiency of applied technologies, maturity of process in division.

- For department of quality of education of higher educational institution: the monitoring task solving to study the level of ability in the students' groups, one of solutions of problems of control of teaching activity, possibility of the automated certification of teachers and correction of educational activity at a higher educational institution.

The received decisions allow carrying out objective diagnostics of quality of training at a higher educational institution, reducing volumes of data demanding the analysis of monitoring inside the university and to reduce economic costs of diagnostics of quality of training when embedding these methods in an automated control system for a higher educational institution.

\section{References}

Avanesov, V. S. (2005). Quality problem pedagogical measurements. Journal of Pedagogical measurement, 4, $3-20$.

Bermus, A. G. (2002). Quality management professional pedagogical education (p. 288). Rostov-on-Don Herzen University Publisher.

Gorbashko, E. A., \& Bonyushko, N. A. (2011). Quality assurance of higher education in the context of international integration (p. 91). St. Petersburg, SPSUEF University Publisher.

Ibragimov, G. I. (2002). State educational standard and system control the quality of graduates. Journal of Vocational education, 1, 10-14.

Ingekamp, K. (1999). Pedagogical diagnostics (p. 240). Moscow Pedagogy Publisher.

Kaynova, E. B. (2005). Criteria of the quality of education: Basic characteristics and methods of measurement (p. 80). Moscow APKiPPRO Publisher.

Matros, D. Sh. (2008). Quality Management in the school based on the standards of GOST R ISO 9000-2001, new information technologies and educational monitoring (p. 288). Moscow Center for Teacher Education.

Muhametzyanova, G. V. (2005). Professional education: Problems of quality and scientific methodical support (p. 319). Kazan Magarif.

Novikov, D. A. (2009). Theory of management of educational systems (p. 419). Moscow Education.

Nuzhdin, V. N. et al. (2003). Strategy and Tactics of quality management education (p. 252). Ivanovo State Power University Publisher.

Potashnik, M. M. (2002). Quality of Education. Problems and management technologies: Questions and answers (p. 352). Moscow Pedagogical Society of Russia. 
Rudinskiy, I. D. (2004). Basics formal-structural simulation training systems and automation testing of pedagogical knowledge (p. 204). Moscow Hotline-Telecom Publisher.

Selezneva, N. A. (2002). Quality of higher education as an object of systematic research. Moscow Research Center of the quality of training, 95.

Subetto, A. I. (2000). Kvalitologiya education (p. 220). Moscow Centre Publisher.

Yakovlev, E. V. (2002). Intrahigh quality management education (p. 390). Chelyabinsk Publisher CSPU.

\section{Copyrights}

Copyright for this article is retained by the author(s), with first publication rights granted to the journal.

This is an open-access article distributed under the terms and conditions of the Creative Commons Attribution license (http://creativecommons.org/licenses/by/3.0/). 